\title{
Editorial
}

Coronavirus disease 2019 in otolaryngology: special issue: J Fishman, E Fisher

\section{Main Articles}

Union of the European Phoniatricians' position statement on the exit strategy of phoniatric and laryngological services:

staying safe and getting back to normal after the peak of coronavirus disease 2019 (issued on 25th May 2020): A Geneid,

T Nawka, A Schindler, H Oguz, V Chrobok, O Calcinoni, A am Zehnhoff-Dinnesen, K Neumann, M Farahat,

T Abou-Elsaad, M Moerman, E Chavez, J Fishman, $R$ Yazaki, B Arnold, Z Frajkova, S Graf, C Pflug, J Drsata,

G Desuter, C Samuelsson, M Tedla, D Costello, E Sjögren, M Hess, T Kinnari, J Rubin

The UK national registry of ENT surgeons with coronavirus disease 2019: K Stephenson, LJ Sowerby, C Hopkins, N Kumar

Restructuring ENT out-patient services during the coronavirus disease 2019 pandemic - an iterative approach:

M Halliwell-Ewen, B Atkin, CT Huins, CL Dalton

North East London coronavirus disease 2019 protocol for diagnostics in two-week wait head and neck cancer patients:

E Warner, DW Scholfield, A Adams, P Richards, S Ali, J Ahmed, K Ghufoor

The impact of coronavirus disease 2019 on head and neck cancer services: a UK tertiary centre study: $R$ Taylor,

E Omakobia, S Sood, RJ Glore

Tracheostomy in the coronavirus disease 2019 patient: evaluating feasibility, challenges and early outcomes of the

14-day guidance: N Glibbery, K Karamali, C Walker, I Fitzgerald O'Connor, B Fish, E Irune

Survey and analysis of knowledge, attitude and practice among otolaryngologists in a state in eastern India in relation to the coronavirus disease 2019 pandemic: S Banerjee, S Sarkar, SN Bandyopadhyay

Smell and taste recovery in coronavirus disease 2019 patients: a 60-day objective and prospective study: LA Vaira,

C Hopkins, M Petrocelli, JR Lechien, CM Chiesa-Estomba, G Salzano, M Cucurullo, FA Salzano, S Saussez,

P Boscolo-Rizzo, F Biglioli, G De Riu

Relationship between anosmia and hospitalisation in patients with coronavirus disease 2019: an otolaryngological perspective: $\mathrm{H} \mathrm{Avcl,} \mathrm{B} \mathrm{Karabulut,} \mathrm{A} \mathrm{Farasoglu,} \mathrm{E} \mathrm{Boldaz,} \mathrm{M} \mathrm{Evman}$

Epistaxis as a marker for severe acute respiratory syndrome coronavirus-2 status - a prospective study: MH Hussain, M Mair, P Rea

Acute mastoiditis in infants aged six months or younger: $P$ Zavras, $S$ Potamianos, $M-Z$ Psarommati, I Psarommatis

Prolonged intra-operative thermal exposure in endoscopic ear surgery: is it really safe?: A Das, S Mitra, P Agarwal, A Sengupta

\section{Short Communications}

Reusable respirators as personal protective equipment during ENT surgery: B Patel, JC Hardman, W Yang, A Robson, G Putnam, A George, V Paleri

Novel technique using surgical scrub sponges to protect the nose and face during prone ventilation for coronavirus disease 2019: TJ Stubington, MS Mansuri

The challenge of performing mastoidectomy using the operating microscope with coronavirus disease 2019 personal protective equipment (PPE): PJ Clamp, SJ Broomfield

Reducing potential aerosol generation in flexible nasolaryngoscopy: a novel method: $J$ Curran, $N$ Calder,

M Yaneza, A lyer

\section{Clinical Record}

Severe acute respiratory syndrome coronavirus-2 in post-laryngectomy patients: case series of four patients:

H Coleman, J Sutherland, N Calder

For further information about this journal please go to cambridge.org/jlo 